\title{
Mechanical Alloying of Fe-Cu Alloys from As-received and Premilled Elemental Powder Mixtures
}

\author{
F.M. Lucas ${ }^{1}$, B. Trindade ${ }^{1}$, B.F.O. Costa ${ }^{2}$, G. Le Caër ${ }^{3}$ \\ ${ }^{1}$ ICEMS, Departamento de Engenharia Mecânica, Universidade de Coimbra, \\ Pinhal de Marrocos, P-3030 Coimbra - Portugal \\ ${ }^{2}$ Departamento de Física, Universidade de Coimbra, P-3000 Coimbra - Portugal \\ ${ }^{3}$ Laboratoire de Science et Génie des Matériaux Métalliques, CNRS UMR 7584, \\ Ecole des Mines, F-54042 Nancy Cedex - France
}

Keywords: $\mathrm{FeCu}$, Mechanical alloying, Mössbauer spectroscopy

\begin{abstract}
We have investigated the effect of premilling elemental powders of $\mathrm{Fe}$ and $\mathrm{Cu}$ on the mixture mechanism of $\mathrm{a} \mathrm{Fe}_{50} \mathrm{Cu}_{50}$ alloy. The alloying process was compared and studied using electron probe microanalysis, X-ray diffraction, scanning electron microscopy and Mössbauer spectroscopy. In both processing routes (with and without premilling), a broad distribution of different local environments of the iron atoms was observed in the Mössbauer spectra of the fcc-FeCu phase. Mössbauer spectra show further that a fcc non magnetic Fe-rich phase is formed transiently besides the bcc-Fe phase. The reactions are slowed down when premilled powders are used as starting powders but similar fcc solid solutions are formed after $16 \mathrm{~h}$ and $32 \mathrm{~h}$ in our milling conditions when as-received and premilled powders are used respectively as starting powders.
\end{abstract}

\section{Introduction}

Alloying of $\mathrm{Fe}$ and $\mathrm{Cu}$ is known to be feasible by high-energy ball-milling [1-3]. We have investigated the preparation of fcc- $\mathrm{Fe}_{50} \mathrm{Cu}_{50}$ alloys by mechanical alloying using two different methods in order to characterise the influence of the mixing mode on the final steady state in our milling conditions. Firstly, the classical method of mechanically alloying of as-received elemental $\mathrm{Fe}$ and $\mathrm{Cu}$ powder blends was used. Later on, as-received powders of $\mathrm{Fe}$ and $\mathrm{Cu}$ were milled separately and then mixed in the required proportions and milled again. Premilling, which modifies the mechanical properties of the initial powders and thus the transfer of energy [4], might change the way $\mathrm{Fe}$ and $\mathrm{Cu}$ are mixed at a nanometric scale. The highest solubility of magnesium in titanium was for instance achieved when both elemental powders were premilled before mechanical alloying [5]. Mechanical mixing by shearing during plastic deformation of powder particles is expected to occur when mixtures of as-received elemental powders are ground while mixing due to welding of the particules should occur predominantly when the powders are premilled separately and then mechanically alloyed together.

\section{Experimental Details}

$\mathrm{Fe}_{50} \mathrm{Cu}_{50}$ alloys were synthesised by mechanical alloying from $\mathrm{Fe}$ and $\mathrm{Cu}$ powders with a nominal purity of $99 \%$ and an average particle size of 60 and $150 \mu \mathrm{m}$, respectively. Milling was performed in a planetary ball mill using hardened steel vial $(250 \mathrm{ml})$ and balls $(15$ balls with $20 \mathrm{~mm}$ diameter each). A ball-to-powder weight ratio of 20:1 was used. The disc rotation speed was $300 \mathrm{rpm}$. Milling was performed in an argon atmosphere to avoid air contamination. The powders were mechanically alloyed in the as-received condition (hereafter "straight condition") and after premilling the elements separately. Thereby, two different batches were obtained. The asmechanically alloyed powders were characterized by means of electron probe microanalysis 
(EPMA), X-ray diffraction (XRD), scanning electron microscopy (SEM) and Mössbauer spectroscopy (MS). The X-ray diffractograms were obtained using Co $\mathrm{K}_{\alpha}$ radiation $(\lambda=0.17889$ $\mathrm{nm})$. Mössbauer spectra were recorded at room temperature in transmission geometry with a spectrometer operating in conventional constant acceleration mode. $\mathrm{A}{ }^{57} \mathrm{Co}$ source in $\mathrm{Rh}$ matrix with a strength of $\approx 10 \mathrm{mCi}$ was used. The spectra were analysed by the method of Le Caër [6], which extracts a hyperfine magnetic field distribution, $\mathrm{P}(\mathrm{B})$, from an experimental spectrum. Lorentzian line-shapes were employed in this procedure.

\section{Results and discussion}

The X-ray diffractograms of the two $\mathrm{Fe}_{50} \mathrm{Cu}_{50}$ samples batches as a function of milling time are presented in fig. 1 . In both cases, a broadening of the diffraction peaks of both $\mathrm{Cu}$ and $\mathrm{Fe}$ occurs gradually with increasing milling time. The diffraction intensity of Fe decreases more rapidly compared with that of $\mathrm{Cu}$. The diffraction peaks of $\mathrm{Cu}$ are no longer observed after different periods of time depending on the milling process. In the straight process, Fig. 1(a), the X-ray reflections of Fe are no longer visible for milling times longer than $8 \mathrm{~h}$. In the second process (premilled powders), Fig. 1(b), vanishing of the Fe diffraction lines occurs for longer milling times, i.e longer than 16h. In both processes, iron is incorporated in the fcc- $\mathrm{Cu}$ structure, giving rise to a fcc- $\mathrm{Cu}(\mathrm{Fe})$ solid solution whose diffraction peaks shift to higher angles with milling time as a consequence of a steadily increasing solubility of iron in copper. In equilibrium, the elements $\mathrm{Fe}$ and $\mathrm{Cu}$ are immiscible and the equilibrium $\mathrm{Fe}-\mathrm{Cu}$ phase diagram does not exhibit intermediate phases. The lattice parameters of the fcc- $\mathrm{Cu}(\mathrm{Fe})$ solid solutions obtained after the two milling processes (straight and premilled powders) are equal to 0.3636 and $0.3635 \mathrm{~nm}$, respectively, which correspond to expanded fcc-Cu lattices $(0.3615 \mathrm{~nm})$. In spite of the larger atomic size of copper when compared to iron, the fcc $\mathrm{Cu}$ lattice is expanded by the incorporation of iron atoms in agreement with previous works [1-3]. Harris et al [7] propose a model in which the strong interaction between like atom pairs $(\mathrm{Fe}-\mathrm{Fe}, \mathrm{Cu}-\mathrm{Cu})$ provides Coulombic forces which establish geometrical limitations prohibiting the unlike $\mathrm{Fe}-\mathrm{Cu}$ pairs from coming any closer than the measured distances. In fact, the dilated bonds measured between $\mathrm{Cu}$ and $\mathrm{Fe}$ indicate that either a very weak interaction or a repulsion exists between unlike neighbours as a result of a positive heat of mixing in this system [9].
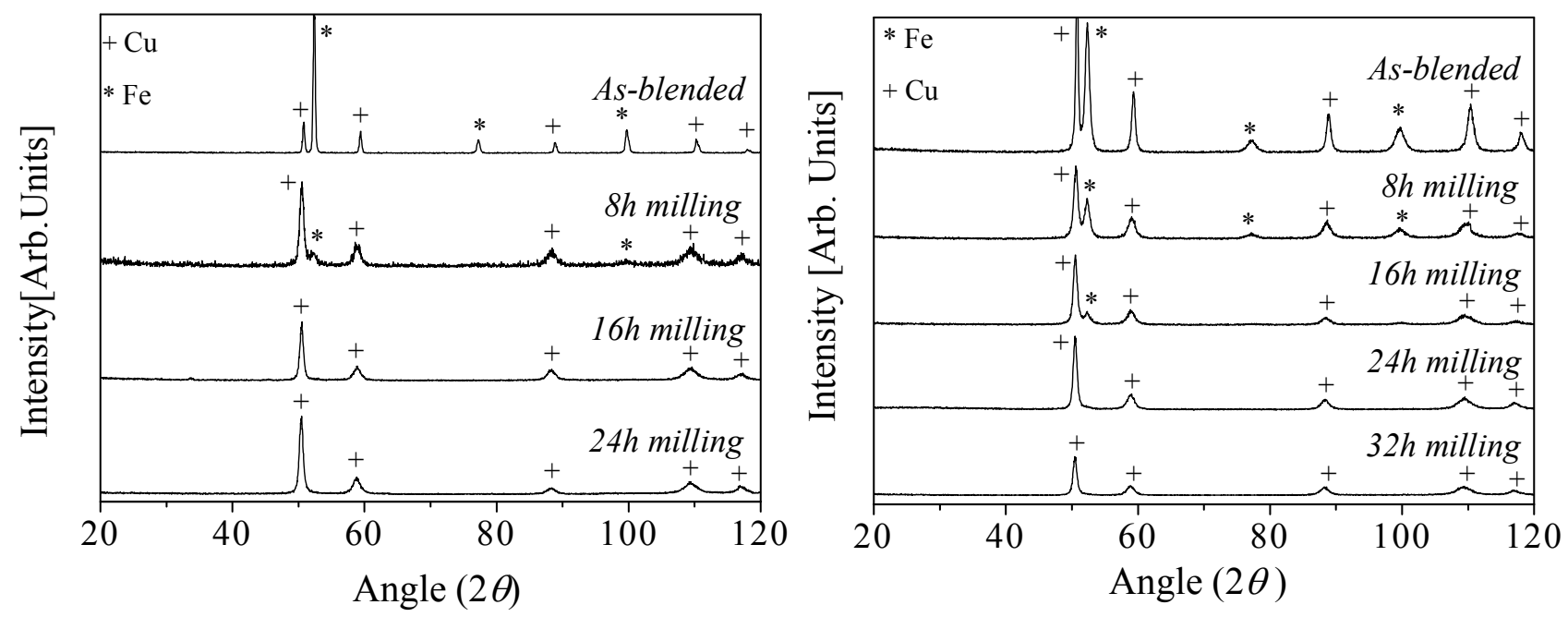

Figure 1 - X-ray diffractograms of the two $\mathrm{Fe}_{50} \mathrm{Cu}_{50}$ samples batches as a function of milling time. (a) straight condition, (b) premilled powders. 
The crystallite size and microstrains of the final state of the milled powders, determined from the width of X-ray diffraction peaks using the Williamson-Hall method [10], are $23 \mathrm{~nm}$ and 1.5\% (straight process) and $13 \mathrm{~nm}$ and 1\% (premilled powders), respectively.

Figure 2 shows the Mössbauer spectra of the two sample batches, i.e. (a) straight and (b) premilled, for different times of milling. Three different components can be distinguished. The first is a broadened sextet caused by the occurrence of a hyperfine magnetic field distribution, which is attributed to the fcc-FeCu phase. This indicates that a broad distribution of environments of iron atoms exists in the fcc- $\mathrm{FeCu}$ phase and demonstrates that $\mathrm{Fe}$ and $\mathrm{Cu}$ were alloyed at an atomic level. The second is a sextet with a hyperfine field of $33 \mathrm{~T}$ characteristic of the bcc-Fe phase. The bcc-Fe phase was not detected by XRD for milling periods equal or longer than 16h (straight process) or than $24 \mathrm{~h}$ (premilled powders). This can be explained by the very small amount and the small crystallite size of this residual phase which may at least partly come from a contamination by milling tools. The third contribution is a single line with an IS $=-0.09 \mathrm{~mm} / \mathrm{s}$ characteristic of the fcc-Fe phase [11]. This phase was not detected by XRD, likely for similar reasons.

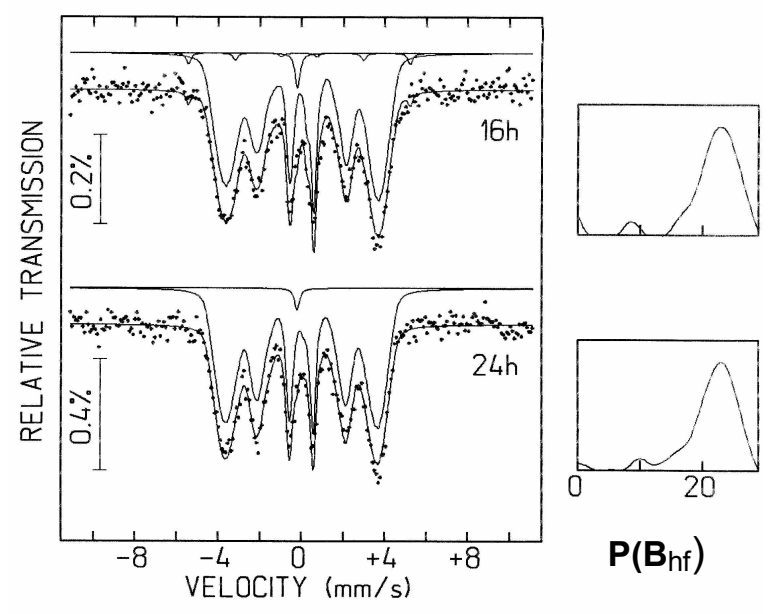

(a)

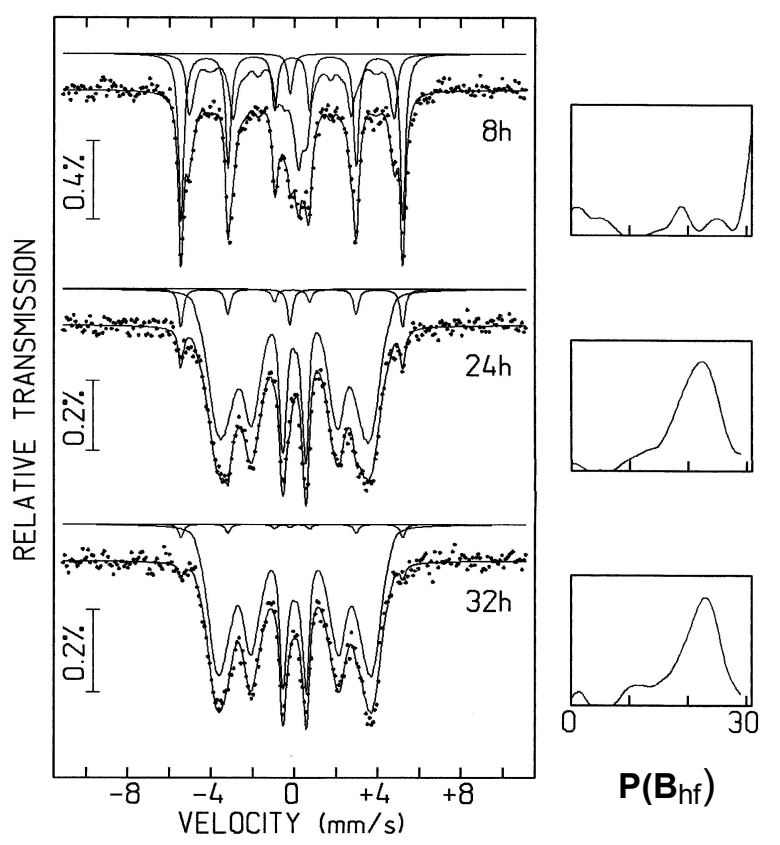

(b)

Figure 2 - Room temperature ${ }^{57} \mathrm{Fe}$ Mössbauer spectra and the corresponding hyperfine magnetic field distributions for $\mathrm{Fe}_{50} \mathrm{Cu}_{50}$ samples after different milling times. (a) Powders mechanically alloyed in the as-received condition, (b) Fe and $\mathrm{Cu}$ premilled separately.

Figures 3 and 4 shows some SEM micrographs of the particle morphologies as a function of milling time. As can be seen, in the final state the samples have a pellet shape of about $0.7 \mathrm{~mm}$ in diameter and about $0.3 \mathrm{~mm}$ in thick, independently of the milling process (Fig. 3 (a) and (b)). This shape is obtained earlier in the straight milling process. Fig. 4 compares the morphologies of the particles milled for $1 \mathrm{~h}$ using the two milling processes. In the case of inverted back-scattered (BE) images, black and white zones correspond to copper and iron respectively. In the straight milling process, mixing is faster than in the second process, in which plates of iron and copper can be easily differentiated. Quantitative electron microprobe analysis confirms these observations. No significant compositional variations were observed in particles obtained from the straight process after $1 \mathrm{~h}$ of milling. By contrast, there are some compositional fluctuations in particles alloyed from premilled powders for $1 \mathrm{~h}$ (Fe- and $\mathrm{Cu}$-rich zones). Some iron particles were detected in the latter 
powders. The $\mathrm{Cu}$-rich particles are actually $\mathrm{Cu}(\mathrm{Fe})$ solid solutions with a significant iron amount. This means that, contrarily to the bcc-Fe structure, there is an incorporation of iron in the fcc-Cu structure from the beginning of the milling process.

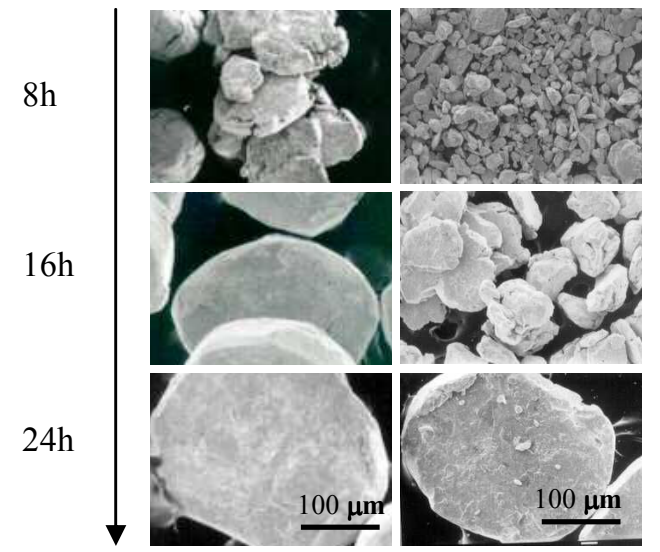

(a)

(b)

Figure 3 - SEM particle morphologies (70x) as a function of milling time. (a) straight condition, (b) with premilling.

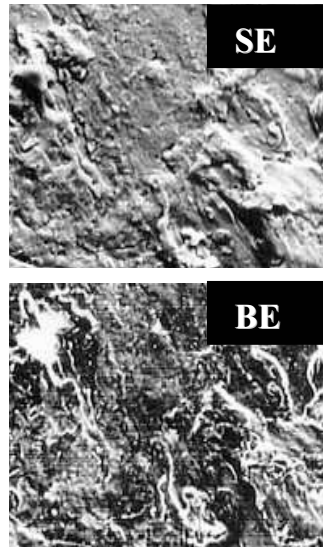

(a)

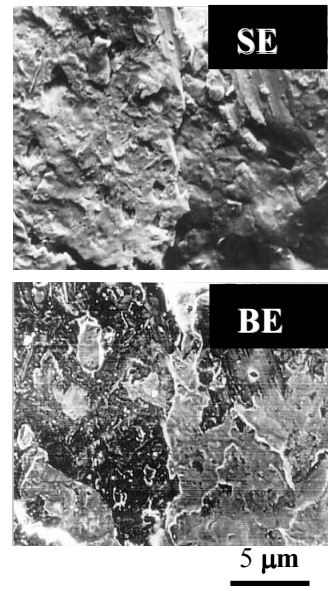

(b)
Figure 4 - SEM images (1500x) of the particles milled for $1 \mathrm{~h}$. (a) straight condition, (b) with premilling. $\mathrm{SE}=$ secondary electrons, $\mathrm{BE}=$ back-scattered electrons.

\section{Conclusions}

The XRD and MS results show that it is possible to incorporate iron in the fcc-Cu matrix by the two milling processes used in this work. In both procedures, a broad distribution of different local environments of iron atoms was observed in the Mössbauer spectra of the fcc-FeCu phase. This indicates that $\mathrm{Fe}$ and $\mathrm{Cu}$ are mixed at an atomic level. Mössbauer spectra show further that a fcc non magnetic Fe-rich phase is formed transiently besides the bcc-Fe phase. The reactions are slowed down when premilled powders are used as starting materials. In our milling conditions, similar fcc solid solutions are formed for $24 \mathrm{~h}$ (straight condition) and 32h (premilled powders).

\section{Acknowledgements}

This work was partly funded by the Portugese-French ICCT-Ambassade de France à Lisbonne cooperation. The authors also thank Pierre Delcroix (LSG2M) for useful suggestions.

\section{References}

[1] P. Crespo and A. Hernando, Recent Res. Devel. Nanostructures, 1 (1999) 63

[2] L. B. Hong and B. Fultz, Acta mater. 46 (1998) 2937

[3] J.Y. Huang, J. Mater. Sci., 31 (1996) 4165

[4] D. Choulier, R. Rahouadj and E. Gaffet, Ann. Chim. Sci. Mat. 22 (1997) 351

[5] E. Zhou, C. Suryanarayana and F.H. Froes, Mater. Lett. 23 (1995) 27

[6] G. Le Caër and J.M. Dubois, J. Phys. E 12 (1979) 1083

[7] V.G. Harris, K.M. Kemner, B.N. Das, N.C. Koon, A.E. Ehrlich, J.P. Kirkland, J.C. Woicik, P. Crespo, H. Hernando, A. Garcia Escorial, Phys. Rev. B 54 (1996) 6929.

[8] W.B. Pearson, in The Chemical Structure of Solids, Vol. I, edited by N.B. Hannay (Plenum, New York, 1976), Vol. I p.115.

[9] E. Ma, H.W. Sheng, J.H. He and P.J. Schilling, Mater. Sci. Eng. A 286 (2000) 48.

[10] G.Williamson and W.H. Hall, Acta Met. 1 (1952) 22

[11]R. Halbauer and U. Gonser, J. Magn. Magn. Mater. 35 (1983) 55 